\title{
Laryngeal Surface of the Epiglottis
}

National Cancer Institute

\section{Source}

National Cancer Institute. Laryngeal Surface of the Epiglottis. NCI Thesaurus. Code C160979.

The surface of the epiglottis that is oriented toward the larynx. 